\title{
Checking it twice: an evaluation of checklists for detecting medication errors at the bedside using a chemotherapy model
}

\author{
Rachel E White, ${ }^{1}$ Patricia L Trbovich, ${ }^{1}$ Anthony C Easty, ${ }^{2}$ Pamela Savage, ${ }^{3}$ \\ Katherine Trip, ${ }^{3}$ Sylvia Hyland ${ }^{4}$
}

${ }^{1}$ Healthcare Human Factors Group, Centre for Global eHealth Innovation, University Health Network, Toronto, Canada ${ }^{2}$ Healthcare Human Factors Group, Centre for Global eHealth Innovation, University Health Network, University of Toronto, Mount Sinai Hospital, Toronto, Canada

${ }^{3}$ Princess Margaret Hospital, University Health Network, Toronto, Canada

${ }^{4}$ Institute for Safe Medication Practices Canada, Toronto, Canada

\section{Correspondence to}

Ms Rachel E White, Healthcare Human Factors Group, Centre for Global eHealth Innovation, University Health Network, 4th Floor, R Fraser Elliott Building, 190 Elizabeth Street, Toronto, Ontario M5G 2C4, Canada; rachel.white@uhn.on.ca

Accepted 4 January 2010 Published Online First 19 August 2010

\section{(2) UNLOCKA}

This paper is freely available online under the BMJ Journals unlocked scheme, see http:// qshc.bmi.com/site/about/ unlocked.xhtml

\section{ABSTRACT}

Objective To determine what components of a checklist contribute to effective detection of medication errors at the bedside.

Design High-fidelity simulation study of outpatient chemotherapy administration.

Setting Usability laboratory.

Participants Nurses from an outpatient chemotherapy unit, who used two different checklists to identify four categories of medication administration errors.

Main outcome measures Rates of specified types of errors related to medication administration.

Results As few as $0 \%$ and as many as $90 \%$ of each type of error were detected. Error detection varied as a function of error type and checklist used. Specific stepby-step instructions were more effective than abstract general reminders in helping nurses to detect errors. Adding a specific instruction to check the patient's identification improved error detection in this category by 65 percentage points. Matching the sequence of items on the checklist with nurses' workflow had a positive impact on the ease of use and efficiency of the checklist. Conclusions Checklists designed with explicit step-bystep instructions are useful for detecting specific errors when a care provider is required to perform a long series of mechanistic tasks under a high cognitive load. Further research is needed to determine how best to assist clinicians in switching between mechanistic tasks and abstract clinical problem solving.

\section{INTRODUCTION}

Adverse drug events have long been established as a significant cause of patient harm, ${ }^{1-4}$ and severe incidents with intravenous drug administration have been well documented. ${ }^{5-8}$ Thus, for certain medications, safety groups are increasingly recommending the use of independent double checks for detecting errors. ${ }^{9-11}$

Independent double checking is a process involving two individuals, in which the responsibility of the second individual is to verify the work performed by the first. ${ }^{12}$ The word 'independent' refers to having a second person follow a series of steps to arrive at a calculation or setting; those steps are performed with no prior knowledge of any previous calculation or setting. This approach is thought to reduce the possibility of "confirmation bias,' which occurs when the person checking the medication is likely to see what they expect to see, even if an error has occurred. ${ }^{13}$
Although recommendations for carrying out independent double checks are common, ${ }^{9-11}$ little research has been done on this practice. One frequently cited study established an error detection rate of $93-97 \%{ }^{14}$ but did not include details of how the checks were performed. However, safety organisations have made specific recommendations about how double checks should be performed. For example, some have recommended the second clinician have no knowledge of the calculation or setting before conducting the verification. ${ }^{915}$ Others have recommended the use of a checklist and a formalised process, ${ }^{12}$ but no examples or specific design recommendations have been provided. As such, it is not clear what elements of a double check yield the highest success in detecting errors.

Our hospital's outpatient chemotherapy unit recently introduced a new double checking process and checklist for the verification of ambulatory infusion pump (AIP) settings. Many studies have shown the effectiveness of checklists in improving patient safety, ${ }^{16-18}$ but a recent review found very little research on the effective design of checklists. ${ }^{19}$

In the study reported here, we used an experimental approach to examine what components of a double check contributed to effective detection of medication errors with the aim of generating evidence-based recommendations for designing supportive tools. Given the opportunity for study in our hospital and the risks associated with chemotherapy administration, ${ }^{20}$ the clinical model for this research was chemotherapy.

\section{METHODS}

It was essential to begin this research with a solid understanding of the context in which error checking takes place, as well as the specific risks associated with administering chemotherapy by AIP. Hence, using the approach of contextual enquiry, ${ }^{21} 22$ we observed 13 registered nurses in the unit for $30 \mathrm{~h}$ We then identified all failures that could occur and classified these into four categories (table 1$){ }^{23}$

\section{CHECKLIST DESIGNS}

Two checklists were compared in this study. One had been in use in the unit for several months. The new checklist was a revision of the old checklist and was based on our observations of how it was being used

\section{Old checklist}

This checklist had been designed to ensure that the second nurse had no knowledge of the medication 
Table 1 Failure modes for chemotherapy administered via ambulatory infusion pumps

\begin{tabular}{|c|c|c|c|}
\hline Category & Failure mode & Severity & Probability \\
\hline \multirow[t]{3}{*}{$\begin{array}{l}\text { Pump-programming } \\
\text { error }\end{array}$} & $\begin{array}{l}\text { Nurse enters incorrect } \\
\text { rate when programming pump }\end{array}$ & Catastrophic & Occasional \\
\hline & $\begin{array}{l}\text { Nurse enters incorrect volume } \\
\text { when programming pump }\end{array}$ & Minor & Occasional \\
\hline & $\begin{array}{l}\text { Nurse enters incorrect lock level } \\
\text { (or forgets to lock) when } \\
\text { programming pump }\end{array}$ & Minor & Occasional \\
\hline $\begin{array}{l}\text { Patient-identification } \\
\text { error }\end{array}$ & $\begin{array}{l}\text { Nurse picks up medications } \\
\text { from pharmacy and administers } \\
\text { to wrong patient }\end{array}$ & Catastrophic & Occasional \\
\hline \multirow[t]{2}{*}{$\begin{array}{l}\text { Mismatch between } \\
\text { drug label and order }\end{array}$} & $\begin{array}{l}\text { Prepared medication does } \\
\text { not match order because } \\
\text { physician has changed order } \\
\text { since pharmacy printed it and } \\
\text { prepared the medication }\end{array}$ & Moderate & Frequent \\
\hline & $\begin{array}{l}\text { Prepared medication does } \\
\text { not match order because } \\
\text { pharmacy made error when } \\
\text { transcribing the order into } \\
\text { pharmacy system }\end{array}$ & Catastrophic & Occasional \\
\hline Clinical decision error & $\begin{array}{l}\text { Physician orders an inappropriate } \\
\text { prescription, and this is not } \\
\text { detected by subsequent care } \\
\text { providers. Error could be } \\
\text { with any aspect of the } \\
\text { drug order: dose weight } \\
\text { (mg), dose volume (ml), } \\
\text { infusion rate, infusion } \\
\text { volume, etc. }\end{array}$ & Catastrophic & Uncommon \\
\hline
\end{tabular}

order before viewing the pump settings, ${ }^{915}$ and was meant to be conducted as follows (figure 1):

The first nurse checks the 'five rights' between the order and the drug label, and programmes the pump according to the label.

The second nurse copies all values directly from the pump screen to the checklist, and then verifies the checklist against the label.

The second nurse checks the drug label against the order to ensure the drug has been prepared as prescribed.

The second nurse returns the pump and the checklist to the first nurse, who checks the label against the patient's armband and administers the medication to the patient.

During observations, we noticed the checklist was not routinely used as intended. Specifically, the second nurse tended to look cyclically at the label, order and pump for each item and then write its value onto the checklist. This approach meant that the nurse had knowledge of what to expect on the pump screens before looking at the pump, hence compromising the independence of the check.

We believed the reason for this behaviour was the placement of the items 'total dose' and 'infusion duration' at the beginning of the list. This information was only available on the drug label and order, not the pump. Thus, to complete the checklist from top to bottom, nurses had to look first at the order or label.

We also observed that despite instructions at the top of the form to check the label to the patient's armband, nurses did not routinely check patient identity.

\section{New checklist}

Based on our observations, we refined the checklist (figure 2). To address the issue of the independence, the checklist was rearranged so that the first six items of the checklist mirrored the exact sequence of the infusion pump prompts.
To address the potential for administering a medication to the wrong patient, we embedded a specific item into the checklist, reminding the nurse to check the patient's identity from the armband against the drug label.

We were concerned that clinical decision errors would be missed with the existing checklist, since there were no reminders to check for this error type. We thus added a reminder of the 'five rights' of medication administration, along with a graphic stating 'STOP! Knowing all you know, does this order make sense to you?

\section{PROCEDURE}

To compare the two checklists, we simulated error checking for intravenous chemotherapy in a usability laboratory with oneway mirrors and cameras (figure 3). Ten nurses from the unit were recruited to participate. Furniture, patient charts, interruptions and ambient noise were used to replicate their clinical environment and tasks.

A nurse actor programmed the pumps and created a realistic teamwork environment, two actors played the roles of patients with cancer, and a mannequin was used as an additional patient (figure 4).

The focus of the experiment was on the second nurse's ability to detect errors using the checklists. They had to care for their own patients and check the other nurse's pumps. To create a sense of realism, they were regularly interrupted by the actors' unscripted conversations.

Each participant used the old and new checklists: half used the old checklist first. In total, each participant checked 14 pumps (seven with each double checking method) (table 2). Errors were also counterbalanced between participants and carefully matched between the two checklists.

Two observers collected data on the number and type of errors detected and time taken to complete each check.

\section{DATA ANALYSIS}

Error-detection rates were analysed using a 2 (checklist type; old vs new) $\times 4$ (error type; pump programming vs mismatch vs patient ID vs clinical decision) repeated-measures analysis of variance (ANOVA) with an $\alpha$ level of 0.05. Differences between means for each of the four error types were assessed using post-hoc pairwise comparisons with the Bonferroni correction. Time to complete the checks was analysed using a one-way (checklist type; old vs new) repeated-measures ANOVA with an $\alpha$ of 0.05

\section{RESULTS}

Overall, the new checklist helped nurses to detect more errors of any type (55\%; 71/130) than the old checklist (38\%; 49/130) $(F(1,9)=26.64, \mathrm{p}<0.01)$.

\section{ERROR DETECTION}

There was a significant interaction between checklist type and error type $(F(3,27)=7.31, \mathrm{p}<0.01)$ (figure 5$)$.

\section{Errors in pump programming}

There was no significant difference in detection of pump programming errors between the checklists $(90 \%$ with the old checklist (51/60); and 80\% with the new checklist (48/60)) ( $p>0.05)$. We expected that the change in the order of items on the checklist would improve the rate of error detection by eliminating confirmation bias, but this was not the case. 
Figure 1 Checklist for independent double checking introduced in the chemotherapy nursing unit (old checklist).

\section{Ambulatory Infusion Pump (AIP) For Continuous Infusion}

Addressograph

RN: 1. Check medication label to the electronic or paper physician's order or prescription. 2. Set AIP pump according to the label.

3. Check settings and enter " $\checkmark$ " in the "1st RN" boxes.

1. Look at the AIP's screen and copy pump settings values into the " $2 \mathrm{nd} R \mathrm{R}$ " boxes.

$2^{\text {nd }}$ RN: 2. Check medication label against cassette/bag and patient's name, MRN and all AIP settings.

3. Check label to the electronic or paper physician's order or prescription.

st $R$ : 1. If NO discrepancy, check label to patient's arm band, if correct start medication.

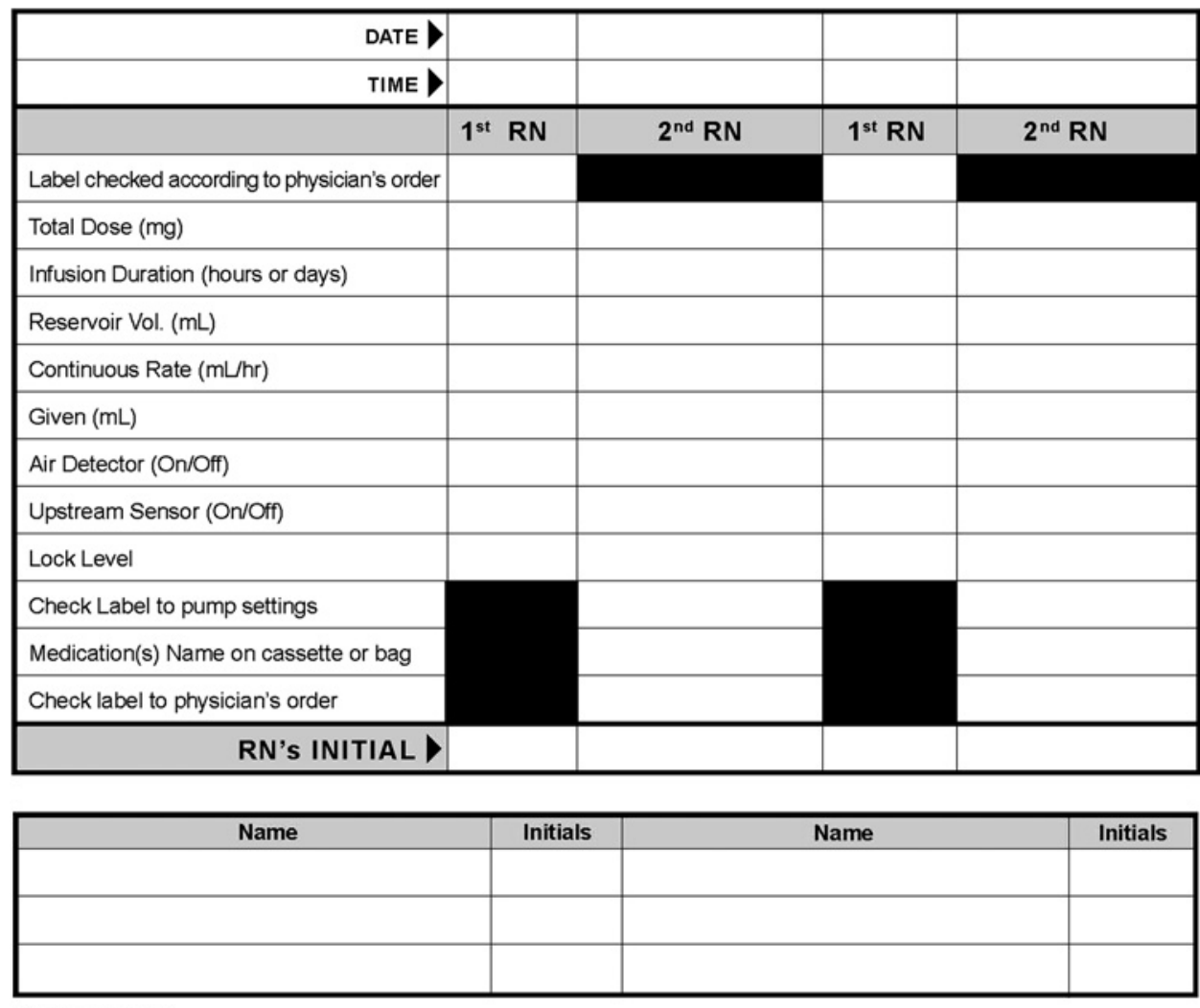

Form D-2600 (19/08/2006)

\section{Errors in patient identification}

Detection of identification errors with the new checklist $(80 \%$; $16 / 20)$ was significantly higher than with the old checklist $(15 \%$; $3 / 20)(p<0.01)$. Thus, the addition of the specific item on the checklist (ie, "check MRN (medical record number) and name from armband to medication label') had a positive impact on error detection.

\section{Mismatches between order and label}

Overall, detection of mismatch errors was low, and there was no significant difference between the old checklist $(45 \% ; 9 / 20)$ and the new checklist $(60 \% ; 12 / 20)$ ( $p>0.05)$. Since no changes were made to this error detection task on the checklist, we were not surprised by this result.

\section{Clinical decision errors}

Neither checklist helped nurses to identify clinical errors (none of these was detected; 0/30). Thus, the addition of the general reminder to stop and think critically had no impact on error detection $(\mathrm{p}>0.05)$.

\section{Efficiency}

On average, it took nurses 2:16 (minutes:seconds) to complete a check with the old checklist and 1:55 with the new checklist. This $21 \mathrm{~s}$ improvement was not statistically significant ( $p>0.05)$. Thus, despite the addition of a step for verifying patient identity that required the nurse to travel to the bedside, there was no difference in efficiency between the two checklists. Further, nurses commented that the new checklist seemed easier to use.

\section{DISCUSSION}

In this study we aimed to determine which checklist features impacted nurses' ability to detect different types of errors in a double checking process. We found a wide range in errordetection rates: as few as $0 \%$ and as many as $90 \%$ of errors were identified, depending on the type of error and the checklist used.

\section{SPECIFIC REMINDERS ARE EFFECTIVE BUT NOT FAILSAFE}

When the checklist included specific instructions detailing what to look for and where to look (such as the pump programming 
Figure 2 Redesigned checklist for performing double checks (new checklist).
Ambulatory Infusion Pump (AIP)

For Continuous Infusion

\begin{tabular}{|c|c|c|c|c|c|c|c|}
\hline 1st RN: & \multicolumn{7}{|c|}{$\begin{array}{l}\text { 1. Check medication label to the electronic or paper physician's order or prescription. Ensure label has correct: patient } \\
\text { name, MRN, drug, dose, rate ( } m L / h r) \text {, route, tota/ volume, total dose }(m g) \text {. } \\
\text { 2. Set AlP pump according to the label. " } \\
\text { 3. Check settings and enter " } \checkmark " \text { in the "1st RN" boxes. }\end{array}$} \\
\hline $2^{\text {nd }}$ RN: & \multicolumn{7}{|c|}{$\begin{array}{l}\text { 1. Copy settings from AIP screen into the "2nd RN" boxes. } \\
\text { 2. Check copied values against label. } \\
\text { 3. Check label to the electronic or paper physician's order or prescription. }\end{array}$} \\
\hline $1^{\text {th }} \mathrm{RN}$ : & \multicolumn{7}{|c|}{$\begin{array}{l}\text { If no discrepancy, check label to patient's arm band. Start medication. } \\
\text { If there is a discrepancy, discuss with } 2 \text { nd } R N \text {, reprogram pump and repeat independent } \\
\text { double-check with new form. }\end{array}$} \\
\hline \multicolumn{8}{|c|}{ Date , } \\
\hline \multicolumn{8}{|c|}{ Time : } \\
\hline & & $1^{\text {st }} \mathrm{RN}$ & $2^{\text {nd }} \mathrm{RN}$ & $1^{\text {t3 }} \mathrm{RN}$ & $2^{\text {nd }} \mathrm{RN}$ & $1^{\text {st }} \mathrm{RN}$ & $2^{\text {nd }} \mathbf{R N}$ \\
\hline \multicolumn{8}{|c|}{ Reservoir volume (mL) } \\
\hline \multicolumn{2}{|c|}{ Continuous rate $(\mathrm{mL} / \mathrm{mr})$} & $\checkmark$ & & r & & r & \\
\hline \multicolumn{2}{|c|}{ Given (mL) } & s & & v & & $\mathrm{z}$ & \\
\hline \multicolumn{2}{|c|}{ Air Detector (On/Off) } & r & & 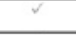 & & v & \\
\hline \multicolumn{2}{|c|}{ Upstream Sensor (On/Off) } & 2 & & v & & v & \\
\hline \multicolumn{2}{|c|}{ Lock Level } & 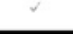 & & $\mathrm{z}$ & & r & \\
\hline \multicolumn{2}{|c|}{ Check pump settings against medication label } & & $\checkmark$ & & $\checkmark$ & & $\checkmark$ \\
\hline \multicolumn{2}{|c|}{ Check me dication label against physician's order } & & 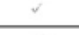 & & 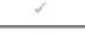 & & $\checkmark$ \\
\hline \multicolumn{2}{|c|}{ Check MRN \& name from ammband to medication label } & & 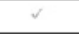 & & 5 & & 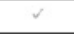 \\
\hline \multicolumn{8}{|c|}{ Unclamp tubing prior to patient discharge } \\
\hline & RN's Initial & & & & & & \\
\hline
\end{tabular}

\begin{tabular}{|c|c|c|c|}
\hline Name & Initials & Name & Initials \\
\hline & & & \\
\hline & & & \\
\hline
\end{tabular}

The 5 rights of medication administration:

1. Right medication

2. Right dose

3. Right route

4. Right time

5. Right patient

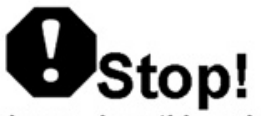

Knowing all that you know, does this order make sense to you?

items on both checklists and the patient identification item on the new checklist), detection rates were much higher (80-90\%) than when the instructions were less specific. For example, the

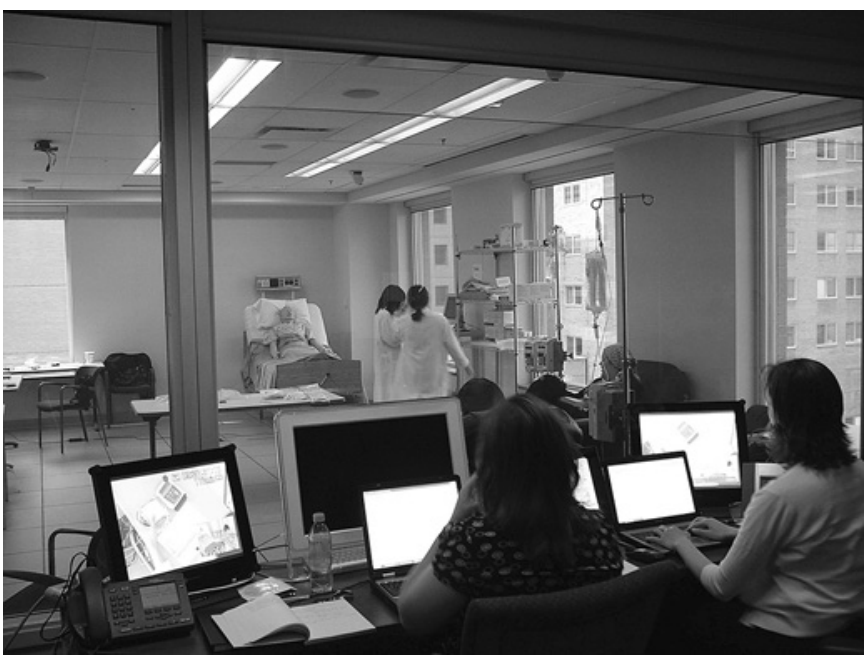

Figure 3 Usability laboratory. items for detecting mismatches between the order and label simply instructed nurses to check the medication label against the original order but did not specify which data points to check;

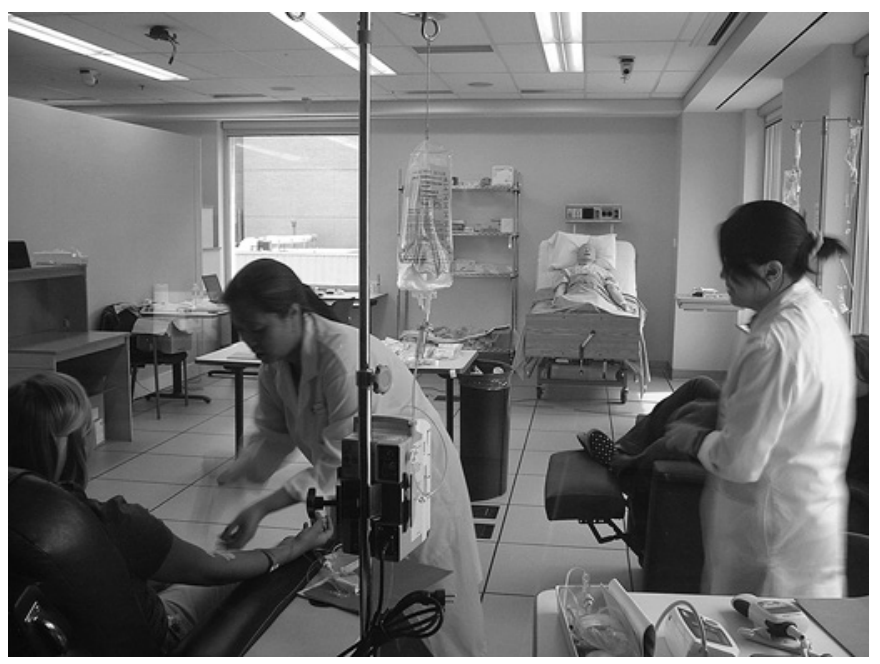

Figure 4 Nurse participant interacting with a patient actor as the confederate nurse interrupts in the simulated outpatient chemotherapy environment. 
Table 2 Errors used in laboratory experiment

\begin{tabular}{|c|c|c|}
\hline Error type & Explanation & Example \\
\hline $\begin{array}{l}\text { Pump-programming } \\
\text { error }\end{array}$ & $\begin{array}{l}\text { First nurse programmed } \\
\text { the pump incorrectly. } \\
\text { Error in rate, volume or } \\
\text { lock level. }\end{array}$ & $\begin{array}{l}\text { Rate has been programmed } \\
\text { as } 0.3 \mathrm{ml} / \mathrm{h} \text {. } \\
\text { The correct rate is } 3 \mathrm{ml} / \mathrm{h} \text { as } \\
\text { shown on order and label. }\end{array}$ \\
\hline $\begin{array}{l}\text { Patient-identification } \\
\text { error }\end{array}$ & $\begin{array}{l}\text { Two patients in the unit } \\
\text { have similar names } \\
\text { and/or identifiers. } \\
\text { The wrong patient is in } \\
\text { the bed, or the first } \\
\text { nurse picked up } \\
\text { the wrong medication } \\
\text { from pharmacy. }\end{array}$ & $\begin{array}{l}\text { Order and label are for Ross Kelly, } \\
\text { MRN (medical record } \\
\text { number) \#7004589. Patient } \\
\text { wristband reads Kelly Ross, } \\
\text { MRN\#7004591. }\end{array}$ \\
\hline $\begin{array}{l}\text { Mismatch between } \\
\text { drug label } \\
\text { and order }\end{array}$ & $\begin{array}{l}\text { Physician changed the } \\
\text { order after pharmacy } \\
\text { prepared the drug, } \\
\text { or pharmacy made a } \\
\text { transcription error. Order } \\
\text { is correct, but } \\
\text { label and prepared } \\
\text { drug are incorrect. }\end{array}$ & $\begin{array}{l}\text { Order shows correct dose of } 56 \mathrm{mg} \\
\text { Medication } \\
\text { label shows } 50 \mathrm{mg} .\end{array}$ \\
\hline $\begin{array}{l}\text { Clinical } \\
\text { decision } \\
\text { error }\end{array}$ & $\begin{array}{l}\text { Physician made error } \\
\text { during order entry which } \\
\text { pharmacist did not detect. } \\
\text { All documentation } \\
\text { elements match, but } \\
\text { they are not clinically } \\
\text { appropriate. } \\
\text { Error could be in dose, } \\
\text { volume or rate. }\end{array}$ & $\begin{array}{l}\text { Physician ordered dose } 10 \times \text { too } \\
\text { high. Order and label show } \\
1000 \mathrm{mg} \text {. Correct clinical } \\
\text { value is } 100 \mathrm{mg} \text {. }\end{array}$ \\
\hline
\end{tabular}

the detection rates for this type of error were quite low (45-60\%). The addition of a general reminder to think critically did not help nurses detect any clinical errors. However, adding a specific reminder to check identification from the patient's armband to the drug label improved error detection by 65 percentage points. Thus, specific checklist items can help clinicians identify well-defined, specific errors. Although this is an encouraging finding, it is important to note that $10-20 \%$ of errors still went undetected when they were accompanied by specific instructions, highlighting that human checking processes are not failsafe.

\section{Mechanistic versus abstract tasks}

To detect most of the medication errors in this study, nurses had to mechanistically compare data from one source (eg, rate in $\mathrm{ml} / \mathrm{h}$ on a drug label) against data from another source (eg, rate on an infusion pump in $\mathrm{ml} / \mathrm{h}$ ) to determine if the two matched. In contrast, detection of clinical decision errors required nurses to compare data from one tangible source (eg, dosage in $\mathrm{mg}$ from a physician's order) against their abstract clinical knowledge of chemotherapy protocols, in the context of a specific patient, to

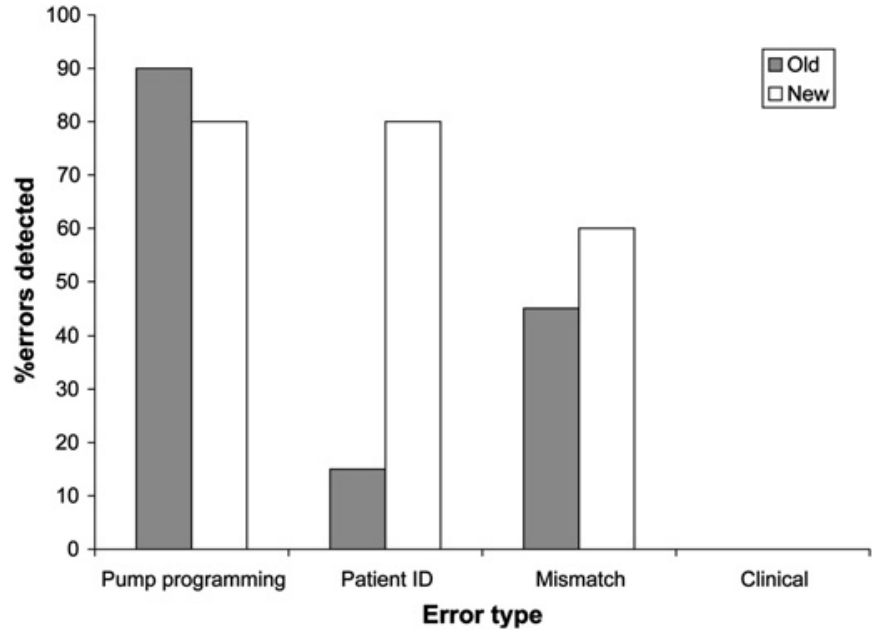

Figure 5 Error-detection rates by error type and checklist type.

determine if all the details of the order were appropriate. Nurses were much better at detecting errors which required mechanistic tasks than those which required critical thought. This difference in performance is consistent with the idea that it is more difficult to detect strategic mistakes than tactical mistakes and that execution errors are more easily detected than method errors. ${ }^{24} 25$

Further, whereas the use of specific instructions helped nurses with mechanistic error-detection tasks, the addition of a general reminder to think critically and remember the 'five rights' of medication administration did not help with the abstract task. Expecting clinicians to mechanistically review several specific aspects of medication administration and then to switch to thinking abstractly about clinical appropriateness may be unrealistic. ${ }^{26}$ If abstract thinking tasks are essential to the final medication administration process, it may be necessary to separate these from the mechanistic tasks and their associated checklists, and to develop other strategies for supporting abstract clinical thought. Further research is needed in this area.

\section{INDEPENDENCE OF DOUBLE CHECKING}

Our revised approach to double checking was designed to encourage nurses to review the pump settings before looking at the prescription details, thus ensuring 'independence' through the elimination of confirmation bias. We believed this approach would result in higher error-detection rates, but found no difference between the old and new checklists in detection of errors in pump programming.

Upon analysis, we realised that the new design did not in fact eliminate confirmation bias; instead, confirmation bias was

Table 3 Steps for developing a checklist for detecting errors

\begin{tabular}{|c|c|}
\hline Step & Task \\
\hline 1 & Determine the errors with high risk or high probability that could reach the bedside, using a technique such as failure modes and effects analysis. ${ }^{18}$ \\
\hline 2 & $\begin{array}{l}\text { Develop specific checklist instructions for each predictable error. Include details of what information to check (eg, dose in mg) and from what sources (physician's order } \\
\text { and drug label). Keep the list short }{ }^{27}{ }^{28} \text { by omitting items with lower risk and lower probability. }\end{array}$ \\
\hline 3 & $\begin{array}{l}\text { If the possibility of an error is abstract or general (eg, error in physician's dosage choice), but the error itself has a high severity or probability, break the error down into } \\
\text { smaller, more specific steps that can be added to the instructions (eg, check dosage on medication order against hospital drug formulary of appropriate adult doses). }\end{array}$ \\
\hline 4 & Determine the workflow of the first and second nurses by observing them working in their natural environment using a technique such as contextual enquiry. ${ }^{21} 22$ \\
\hline 5 & $\begin{array}{l}\text { To encourage efficiency and adoption, assemble the itemised instructions into a checklist that corresponds with their workflow, and use language and terms that match } \\
\text { their existing tools such as the infusion pump screen prompts. }\end{array}$ \\
\hline 6 & $\begin{array}{l}\text { To test and improve the usability of the checklist, recruit a small sample of end users (three to six people) to use the checklist while you observe. If they become } \\
\text { confused, use the checklist in a way that is not anticipated, or readily miss errors, refine the design of the form to be more intuitive, and repeat the testing process. }\end{array}$ \\
\hline 7 & $\begin{array}{l}\text { For each potential error not included on the checklist, develop alternate strategies to prevent it from reaching the bedside. Continue to develop additional strategies for } \\
\text { eliminating all possible errors, even those that can be identified with the checklist, since no human checking process is failsafe. }\end{array}$ \\
\hline
\end{tabular}


shifted from the point of checking the pump to the point of checking the newly completed checklist against the prescription details. Hence, the nurses might still have seen what they expected to see on the order when they verified the (sometimes incorrect) values from the checklist against the prescription. More research is needed to determine how to reduce or eliminate confirmation bias from a human verification process.

For double checking processes, we feel that the most important factor is the completion, by a second individual, of a welldesigned, easy-to-use checklist with a specific item for each specific high-risk error.

\section{DEVELOPING A CHECKLIST FOR DETECTING ERRORS}

On the basis of our findings, we recommend the following steps when developing a checklist for detecting errors (table 3).

\section{Study limitations}

The clinical focus of this research was the detection by nurses of errors related to administration of chemotherapy and did not include other clinical areas. However, we anticipate that our findings and recommendations will be applicable to any context where a care provider must perform a series of mechanistic tasks under a high cognitive load.

For ethical reasons, we were not able to conduct this controlled experiment of error detection in a live clinical environment. Due to the short-term nature of the simulation, we could not determine the long-term effect of the new checklist on nurses' behaviour. Further, participants had been using the 'old' checklist in their unit for some time. We had expected nurses would detect more errors with the old checklist as a result of their familiarity with it, but this was not the case. Another limitation was that interruptions were not scripted but instead flowed naturally from the actors to create a sense of realism, and therefore were more subject to random error than with a script.

\section{CONCLUSIONS}

This research has highlighted that checklists incorporating specific step-by-step instructions are useful for detecting certain errors. Although technological systems can achieve a much higher accuracy and reliability than any human processes, fully integrated and automated systems for complex healthcare are not likely to exist in the near future, and we question whether this goal is ultimately achievable. As such, checklists remain a necessary safety tool for clinicians performing long series of mechanistic tasks and must be designed to support this activity. However, further research is needed to determine how best to assist clinicians in switching between mechanistic tasks and abstract problem solving.

Acknowledgements The following people supported this research: $\mathrm{H}$ Colbert, A Tosine, D Incekol, J Stewart, S Ladak, R Lopez, A Chagpar, C Banez, S Savage, D Grosse Wentrup, C Masino, colleagues at the Centre for Global eHealth Innovation and the study participants.

Funding This research was conducted under a research grant from the Canadian Patient Safety Institute (Grant \# RFA0506284).

Competing interests None.

Ethics approval Ethics approval was provided by the University Health Network, Research Ethics Board, Toronto, Ontario, Canada.

\section{REFERENCES}

1. Kohn LT, Corrigan JM, Donaldson MS, eds. To err is human: building a safer health system. Institute of Medicine, National Academy of Sciences. Washington: National Academy Press, 2000

2. Leape LL, Brennan TA, Laird N, et al. The nature of adverse events in hospitalized patients. results of the Harvard Medical Practice Study II. N Engl J Med 1991;324:377-84.

3. Classen DC, Pestonik SL, Evans RS, et al. Adverse drug events in hospitalized patients: excess length of stay, extra costs, and attributable mortality. JAMA 1997;277:301-6.

4. Bates DW, Cullen DJ, Laird N, et al. Incidence of adverse drug events and potentia adverse drug events: implications for prevention. ADE Prevention Study Group. JAMA 1995:274:29-34

5. Vicente K, Kada-Bekhaled K, Hillel G, et al. Programming errors contribute to death from patient-controlled analgesia: case report and estimate of probability. Can $J$ Anaesth 2003;50:328-32.

6. Institute for Safe Medication Practices. Design flaw predisposes Abbott Lifecare PCA plus II pump to dangerous medication errors. ISMP Medication Safety Alert 2000:5:2. http://www.ismp.org/Newsletters/acutecare/archives/May00. asp\#May31,2000 and http://www.ismp-canada.org/download/safetyBulletins/ ISMPCSB2005-01.pdf (accessed 1 Mar 2010).

7. Institute for Safe Medication Practices. Misprogram a PCA pump? It's easy! ISMP Medication Safety Alert 2004;9:1

8. U, D, Hyland S, et al. Fluorouracil incident root cause analysis report. Toronto: Institute for Safe Medication Practices Canada, 2007.

9. Institute for Safe Medication Practices Canada. Lowering the risk of medication errors: independent double checks. Safety Bulletin 2005;5. http://www.ismp-canada.org/download/safetyBulletins/ISMPCSB2005-01.pdf (accessed 1 Mar 2010)

10. Institute for Safe Medication Practices Canada. Top 10 drugs reported as causing harm through medication error. Safety Bulletin 2006;6. http://www.ismp-canada.org/download/safetyBulletins/ISMPCSB2006-01Top10.pdf (accessed 1 March 2010).

11. Mills PD, Neily J, Kinney LM, et al. Effective interventions and implementation strategies to reduce adverse drug events in the Veterans Affairs (VA) system. Qual Saf Health Care 2008:17:37-46.

12. Institute for Safe Medication Practices. The virtues of independent double checks - they really are worth your time! ISMP Medication Safety Alert 2003;8:1.

13. U, D. Double-checking: does it work? Medication safety alerts. Can J Hosp Pharm 2003:56:167-9.

14. Campbell GM, Facchinetti N. Using process control charts to monitor dispensing and checking errors. Am J Health Syst Pharm 1998;55:946-52.

15. College of Nurses of Ontario. Practice standard: Medication, Toronto, Ontario Canada. 2005. http://www.cno.org/docs/prac/41007 Medication.pdf.

16. Haynes AB, Weiser TG, Berry W, et al. A surgical safety checklist to reduce morbidity and mortality in a global population. N Engl J Med 2009;360:491-9.

17. Lingard L, Espin S, Rubin S, et al. Getting teams to talk: development and pilot implementation of a checklist to promote interprofessional communication in the $\mathrm{OR}$ Qual Saf Health Care 2005:14:340-6.

18. Pronovost $\mathbf{P}$, Needham D, Berenholtz $\mathrm{S}$, et al. An intervention to decrease catheter-related bloodstream infections in the ICU. N Engl J Med 2006;355: 2725-3.

19. Hales B, Terblanche M, Fowler R, et al. Development of medical checklists for improved quality of patient care. Int J Qual Health Care 2008;20910: 22-30.

20. Cohen MR. Preventing medication errors in cancer chemotherapy. In: Cohen MR, ed. Medication errors. 2nd edn. Washington: American Pharmacists Association 2006:445-68.

21. Beyer H, Holtzblatt K. Contextual design: defining customer-centered systems. San Francisco: Morgan Kaufmann Publishers, 1998.

22. Holtblatt K, Burns Wendell J, Wood S. Rapid contextual design: a how-to guide to key techniques for user-centered design. San Francisco: Morgan Kaufmann Publishers Inc., 2004.

23. DeRosier J, Stalhandske E, Bagian JP, et al. Using health care failure mode and effect analysis ${ }^{\mathrm{TM}}$ : the VA National Center for Patient Safety's prospective risk analysis system. Jt Comm J Oual Improv 2002:27:248-67.

24. Reason J. Human error. Cambridge: Cambridge University Press, 1990.

25. Allwood CM. Error detection processes in statistical problem solving. Cogn Sci 1984:8:413-37.

26. Wickens CD, Hollands JG. Engineering psychology and human performance. Uppe Saddle River, NJ: Prentice-Hall, 1999.

27. Degani A, Weiner EL. Cockpit checklists: concepts, design and use. Hum Factors 1993;35:345-59

28. Degani A, Weiner EL. Human factors of flight-deck checklists: the normal checklist NASA technical memorandum \#177549. Moffett Field, CA: NASA Ames Research, 1990. 
21. Belman S, Murphy J, Steiner JF, et al. Consistency of triage decision by call center nurses. Ambul Pediatr 2002;2:396-400.

22. van der Wulp I, van Baar ME, Schrijvers AJP. Reliability and validity of the Manchester Triage System in a general emergency department patient population in The Netherlands: results of a simulation study. Emerg Med J 2008;25:431-4.

23. Dale J, Williams S, Foster T, et al. Safety of telephone consultation for 'non-serious' emergency ambulance service patients. Qual Saf Health Care 2004;13:363-73.

24. Marklund B, Strøm M, Månsson J, et al. Computer-supported telephone nurse triage: an evaluation of medical quality and costs. J Nurs Manag 2007;15:180-7.
25. O'Cathain A, Nicholl J, Sampson F, et al. Do different types of nurses give different triage decisions in NHS Direct? A mixed methods study. $J$ Health Serv Res Policy 2004;9:226-33.

26. Gravel J, Gouin S, Manzano S, et al. Interrater agreement between nurses for the pedriatic Canadian triage and acuity scale in a tertiary care center. Acad Emerg Med 2008;15:1262-7.

27. Olofsson P, Gellerstedt M, Carlstrøm ED. Manchester Triage in Sweden-interrater reliability and accuracy. Int Emerg Nurs 2008:17:143-8.

28. Rutschmann OT, Kossovsky M, Geissbuhler A, et al. Interactive triage simulator revealed important variability in both process and outcome of emergency triage. J Clin Epidemiol 2006;59:615-21.

\section{Corrections}

White RE, Trbovich PL, Easty AC, et al. Checking it twice: an evaluation of checklists for detecting medication errors at the bedside using a chemotherapy model. Qual Saf Health Care 2010;19:562-7.

There are two errors in the results section of this article. The authors state that "the new checklist helped nurses to detect more errors of any type $(55 \% ; 71 / 130)$ than the old checklist $(38 \% ; 49 / 130)$ ". These fractions should not have been included because they are not a logical statistic to report. There were different numbers of planted errors in each category, making the sum of total errors unbalanced: error types which happened to have more planted errors get more weight in the fraction than those with fewer errors. The percentages reported are accurate because the authors took the average error detection percentage across each of the four types- giving them equal weight.

The authors also state that 51/60 errors in pump programming were detected with the old checklist, when it should read 54/60. The percentage value reported was correct $(90 \%)$.

BMJ Qual Saf 2011;20:396. doi:10.1136/qshc.2009.032862corr1

Snijders C, van der Schaaf T W, Klip H, et al. Feasibility and reliability of PRISMAMedical for specialty-based incident analysis. Qual Saf Health Care 2009;18:486-91.

The authors names were incorrectly cited in this paper. The author list should have been as follows; C Snijders, T W van der Schaaf, H Klip, R A van Lingen, W P F Fetter, A Molendijk.

BMJ Qual Saf 2011;20:396. doi:10.1136/qshc.2008.028068corr1 